\title{
IncRNA SNHG6 improves placental villous cell function in an in vitro model of gestational diabetes mellitus
}

\author{
Qian Meng ${ }^{1,2}$, Fang Zhang ${ }^{2}$, Haixia Chen ${ }^{2}$, Wen Xu², Chu Chu², Fengqing Fu ${ }^{1,3}$, Fei Xia ${ }^{1}$
}

\author{
${ }^{1}$ Department of Gynecology and Obstetrics, The First Affiliated Hospital of Soochow \\ University, Suzhou, Jiangsu, China \\ ${ }^{2}$ Maternity Department, Lianyungang Maternal and Child Health Hospital, Lianyungang, \\ Jiangsu, China \\ 3jiangsu Institute of Clinical Immunology, The First Affiliated Hospital of Soochow \\ University, Jiangsu Key Laboratory of Clinical Immunology, Soochow University, \\ Jiangsu Key Laboratory of Gastrointestinal tumor Immunology, Suzhou, Jiangsu, China
}

Submitted: 5 July 2020

Accepted: 5 September 2020

Arch Med Sci

DOI: https://doi.org/10.5114/aoms.2020.100643

Copyright (c) 2020 Termedia \& Banach

\begin{abstract}
Introduction: The purpose of this research was to investigate whether IncRNA SNHG 6 has an effect on the pathogenesis of gestational diabetes mellitus (GDM).

Material and methods: Placental tissue was collected from patients with GDM and from pregnant women without GDM. Expression of IncRNA SNHG6 and EZH2 in the placental tissue was detected by qRT-PCR, immunohistochemistry (IHC), and western blotting. An in vitro cell model for GDM using high-dose glucose was employed to measure relative expression of mRNA and proteins by RT-qPCR and WB assay, and cell viability, apoptosis rate, invasion cell number, and wound healing rate by CCK-8, flow cytometry, transwell assay, and wound healing assay, respectively. Correlation between miRNA-26a-5p and EZH2 was investigated with a dual-luciferase reporter assay.

Results: Compared with the control placenta, IncRNA SNHG6 and EZH2 mRNA expression levels were significantly depressed and $\mathrm{EZH} 2$ protein expression was significantly downregulated in GDM placenta tissues $(p<0.001$, respectively). In the in vitro cell model, IncRNA SNHG6 overexpression significantly improved high-dose glucose-induced HTR-8/SVneo cell function losses, including proliferation, migration, and invasion, by significantly depressing miRNA-26a-5p via regulation of EZH2 expression. The dual-luciferase reporter assay revealed that miRNA-26a-5p could target to EZH2 in HTR-8/ SVneo cells.

Conclusions: Expression of IncRNA SNHG6 in the placenta of patients with GDM is abnormally decreased. Overexpression of IncRNA SNHG6 improved HTR-8/SVneo cell function via regulation of the miRNA-26a-5p/EZH2-H3K27 me3 pathway in an in vitro GDM model.
\end{abstract}

Key words: gestational diabetes mellitus, IncRNA, miRNA, EZH2, HTR-8/ SVneo cell.

\section{Introduction}

Gestational diabetes mellitus (GDM) is a common obstetric complication with an increasing annual incidence owing to changes in maternal age, lifestyle, and diet structure [1, 2]. GDM may induce various adverse

\author{
Corresponding author: \\ Fei Xia \\ Department of Gynecology \\ and Obstetrics \\ The First Affiliated Hospital \\ of Soochow University \\ Suzhou, Jiangsu 215006 \\ China \\ E-mail: xiafei0606@21cn.com
}


outcomes that can pose serious hazards to maternal and fetal health, and can even have long-term impacts on both mothers and infants. It is commonly recognized that GDM has a complex pathogenesis, and this may be attributed to multiple determinants, such as inflammatory factors, insulin resistance, dysfunction of islet $\beta$-cells, genetic factors, environmental factors, and so on $[3,4]$. According to previous studies, despite obvious changes in the expression of many genes with vital functions in patients with GDM, there is no obvious change in the nucleic acid sequences of these genes, and therefore these genes may be involved in the development of GDM through epigenetic mechanisms [5, 6]. Long non-coding RNA (IncRNA) expression is species and spatiotemporal specific; thus there are significant differences in the expression of IncRNA in different species and tissues, and in the same species or tissue at different time periods [7-9]. LncRNA SNHG6 is a recently discovered IncRNA that participates in tumor development by regulating expression of $\mathrm{EZH} 2$, the enzymatic component of polycomb repressive complex 2 (PRC2) [10-12]. EZH2 can induce trimethylation of nucleosomal histone $\mathrm{H} 3$ on lysine side-chain 27 (H3K27me3), and H3K27me3 can then recruit PRC2 to specific gene sites and silence expression of the target gene [13]. Cancer cell biological activities, such as invasion and migration, are similar to the biological activities of placental villous trophoblasts. However, while IncRNA SNHG2 is known to be involved in tumor development, the role of IncRNA SNHG6 remains to be clarified in GDM.

The placenta is an important location for maternal and fetal material exchange. Adhesion and invasion of trophoblasts to the endometrium contribute to placenta formation [14]. Trophoblast dysfunction may play a critical role in the development of pregnancy complications, such as pregnancy hypertension, GDM, fetal growth restriction, abortion, and so on $[15,16]$. Currently, there is limited relevant information on the role of IncRNA SNHG6 and its target miRNA in trophoblasts. The present study aimed to investigate whether IncRNA SNHG6 affects the function of trophoblasts and IncRNA SNHG6's possible regulatory mechanism in GDM.

\section{Material and methods}

\section{Subjects}

Thirty pregnant women with GDM (GDM group) who were hospitalized and 30 pregnant women without GDM (control group) who were treated in our hospital between March 2018 and September 2019 were enrolled in the study. All subjects (24-28 weeks of gestation) performed a 75-g oral glucose tolerance test (OGTT). According to the standard set by the International Association of Diabetes and Pregnancy Study Group, subjects can be diagnosed with GDM when any of the following in dices exceed the threshold value: fasting blood glucose $\geq 5.1 \mathrm{mmol} / \mathrm{l}$; blood glucose $\geq 10.0 \mathrm{mmol} / \mathrm{l}$; or 2-hour postprandial blood glucose $\geq 8.5 \mathrm{mmol} / \mathrm{l}$ [2] Enrolled subjects were all singleton pregnancy, without medical history of hypertension, diabetes, kidney disease, thyroid disease, infection, or cardiovascular disease. The study was approved by the Ethics Committee of our hospital.

\section{Sampling and processing}

Immediately after delivery of the placenta, small pieces of tissue $(2 \mathrm{~cm} \times 2 \mathrm{~cm} \times 2 \mathrm{~cm})$ were dissected from the lobule of the maternal surface of the placenta and were divided into four parts. Collected tissues were washed with phosphatebuffered saline (PBS) and either stored in 2-ml cryopreservation tubes at $-80 \mathrm{C}$ or fixed with $10 \%$ formaldehyde.

\section{Paraffin-embedded section preparation} and hematoxylin and eosin (HE) staining

After fixation, washing, dehydration, transparent processing, waxing, and embedding, paraffinembedded sections were dewaxed, washed, HE stained, dehydrated and transparent processed, followed by sealing with neutral gum and observation of the stained tissues under an optical microscope (CX23, Olympus, Japan).

\section{Immunohistochemistry (IHC)}

Placental tissues $(n=30$ for GDM and control groups) of $1 \mathrm{~cm} \times 1 \mathrm{~cm} \times 1 \mathrm{~cm}$ were prepared into paraffin-embedded sections according to standard procedures and were used to detect expression of $\mathrm{EZH} 2$ in the placenta by the immunohistochemical streptavidin-peroxidase (IHC-SP) method. Briefly, paraffin sections (4 $\mu \mathrm{m}$ thickness) were dewaxed to water, $2 \%$ boiling ethylenediaminetetraacetic acid (EDTA) solution was used for heat-induced, high-pressure antigen retrieval, then $3 \% \mathrm{H}_{2} \mathrm{O}_{2}$ was applied at room temperature for 15 min to block the endogenous peroxidase, and the primary antibody was applied at $4^{\circ} \mathrm{C}$ overnight. All other steps strictly followed the instructions of the staining kit (Keygentec, Nanjing, China), including 3,3'-diaminobenzidine (DAB) staining, hematoxylin re-staining, and sealing. After sealing, five fields of vision (100x magnification) were randomly selected under an inverted phase contrast microscope for observation and photography. Under the microscope, a brownish-yellow granular precipitate was identified as positive staining. The optical density and area of development from each photograph were detected through Image-Pro Plus software, and the integrated optical density (IOD) of each specimen was calculated for semi-quantitative analysis. 


\section{Real-time PCR}

Trizol extraction of total RNA was conducted from placenta samples ( $n=30$ for both GDM and control samples) and cells. ReverTra Ace qPCR RT Kit (TOYOBO, Tokyo, Japan) was utilized for reverse transcription of the cDNA of miR-26a-5p/U6, which was performed at $42^{\circ} \mathrm{C}$ for $60 \mathrm{~min}$ and at $70^{\circ} \mathrm{C}$ for $10 \mathrm{~min}$. SYBR Green Real time PCR Master Mix (TOYOBO, Tokyo, Japan) was applied for detecting gene expression, with reaction conditions of $95^{\circ} \mathrm{C}$ for $10 \mathrm{~min}$, followed by 40 cycles of $95^{\circ} \mathrm{C}$ for $10 \mathrm{~s}, 60^{\circ} \mathrm{C}$ for $20 \mathrm{~s}$, and $72^{\circ} \mathrm{C}$ for $10 \mathrm{~s}$. GAPDH was used as the internal reference gene (Keygentec, Nanjing, China) to detect the expression of EZH2 and IncRNA SNHG6, with amplification conditions of $9^{\circ} 5 \mathrm{C}$ for $3 \mathrm{~min}$, followed by $40 \mathrm{cy}$ cles of $95^{\circ} \mathrm{C}$ for $30 \mathrm{~s}, 56^{\circ} \mathrm{C}$ for $30 \mathrm{~s}$, and $72^{\circ} \mathrm{C}$ for $30 \mathrm{~s}$. At the end of amplification, the fusion curve was analyzed, the average $C t$ value was obtained based on data from three replicates, and the expression multiple of the target gene relative to the internal reference gene was calculated according to the formula: $2^{-\Delta \Delta c t}$ quantitative $(\Delta C t=C t$ (target gene) $-C t$ (internal reference gene), $\Delta \Delta C t=$ experimental group $\Delta C t-$ control group $\Delta C t$ ). Primer sequences are shown in Table I.

\section{Western blot (WB) assay}

Radioimmunoprecipitation assay (RIPA) lysate buffer (containing 1\% PMSF) was used to extract proteins from placental tissues ( $n=30$ for GDM and control samples) and cells, followed by determination of protein concentration using Coomassie Brilliant Blue. Proteins were separated by $10 \%$ SDSPAGE according to the sampling amount of $40 \mu \mathrm{g} /$ well for $90 \mathrm{~min}$ of electrophoresis. SDS-PAGE gel extraction was conducted based on the predictive molecular weight of the target protein, followed by transfer to a polyvinylidene fluoride (PVDF) membrane using a voltage of $320 \mathrm{~mA}$ at $4^{\circ} \mathrm{C}$. Nonspecific sites were blocked with $5 \%$ bovine serum albumin (BSA) for $2 \mathrm{~h}$, then the primary antibody was added for overnight incubation. After washing the membrane with TBST for $15 \mathrm{~min}$, the secondary antibody was added with incubation at room temperature for $1 \mathrm{~h}$. The membrane was then washed three times with TBST, the ECL method was used for development and exposure, and the gray value was scanned and recorded using Image J software (National Institutes of Health, Bethesda, MD, USA). The gray value ratio of the target protein and the internal reference protein was analyzed as the relative expression of the target protein.

\section{Cell culture}

Human chorionic trophoblast cells (HTR-8/SVneo cells; ATCC, USA) were cultured at $37^{\circ} \mathrm{C}$ and $5 \% \mathrm{CO}_{2}$ in Dulbecco's Modified Eagle Medium (DMEM) containing 10\% fetal bovine serum (FBS) and $1 \%$ penicillin and streptomycin double-antibiotic solution. Except for the normal control (NC) group, all cells in other groups were treated with $30 \mathrm{mmol} /$ I glucose.

Experimental groups were as follows: NC group, HTR-8/SVneo cells treated with low dose of glucose; Model group, HTR-8/SVneo cells treated with high dose of glucose; IncRNA group, HTR-8/SVneo cells transfected with IncRNA SNHG6 and treated with high-dose glucose; miR-inhibitor group, HTR8/SVneo cells transfected with miR-26a-5p inhibitor and treated with high-dose glucose; IncRNA + miRNA group, HTR-8/SVneo cells transfected with miR-26a-5p and IncRNA SNHG6 and treated with high-dose glucose.

\section{Cell transfection}

On the day before transfection, actively growing cells were seeded in 6-well plates at a concentration of $3 \times 10^{5}$ cells/well, and transfection was performed when the cell density reached 50-60\%. The nanocomposite formed by P5RHHloaded miRNA, miR-inhibitor, and IncRNA SNHG6, respectively, was used for corresponding transfection, including IncRNA, miR-inhibitor, and IncRNA + miRNA groups (co-transfection of miRNA-26a$5 p$ and IncRNA SNHG6). Subsequent experiments were conducted $24 \mathrm{~h}$ after transfection and after $48 \mathrm{~h}$ of high-dose glucose culture.

Table I. List of RT-PCR primers

\begin{tabular}{|lcc|}
\hline Gene name & Forward primer $\left(\mathbf{5}^{\prime}-\mathbf{3}^{\prime}\right)$ & Reverse primer $\left(\mathbf{5}^{\prime} \mathbf{-} \mathbf{3}^{\prime}\right)$ \\
\hline SNHG6 & TTGAGGTGAAGGTGTATG & GGTAACGAAGCAGAAGTA \\
\hline miR-26a-5p & CGTCCTTCAAGTAATCCAGGA & GCAGGGTCCGAGGTATTC \\
\hline EZH2 & CGAGCTCCTCTGAAGCAAAT & AACCTAGCAATGGCACAGAAA \\
\hline GAPDH & GGATTTGGTGTCGTATTGGGC & CGCTCCTGGAAGATGGTGAT \\
\hline U6 & TGCGGGTGCTCGCTTCGCAGC & CCAGTGCAGGGTCCGAGGT \\
\hline
\end{tabular}




\section{CCK-8 colorimetry for cell proliferation}

After continuous culture for $48 \mathrm{~h}$, cells were seeded in 96-well plates at a concentration of $3 \times 10^{5}$ cells/well and incubated for a further $48 \mathrm{~h}$ at $37^{\circ} \mathrm{C}$ and $5 \% \mathrm{CO}_{2}$. Ten microliters of CCK-8 reagent were then added to each well with mixing, and plates were incubated for $1 \mathrm{~h}$ in the dark. A microplate reader was used to measure the absorbance of the wells at a wavelength of $450 \mathrm{~nm}$ to calculate the cell activity of each experimental group. Six replicates were set for each group.

\section{Flow cytometry for cell apoptosis}

After $48 \mathrm{~h}$ of corresponding treatment for cells in each group, the culture supernatant was discarded and cells were washed twice with cool PBS, followed by digestion with $0.25 \%$ trypsin. Cells were collected by centrifugation at $800 \mathrm{rpm}$ for $5 \mathrm{~min}$, then resuspended in $100 \mu \mathrm{l} 1 \times$ binding buffer. With the addition of $5 \mu$ l of Annexin-V APC and $5 \mu \mathrm{l}$ 7-AAD separately, the cell suspension was mixed well and incubated at room temperature in the dark for $30 \mathrm{~min}$. The cells were analyzed by Well Biotechnology, Co., Ltd. (China) using Cytomics FC500 (Beckman Coulter, Brea, CA, USA).

\section{Transwell assay}

With corresponding cell treatment for $48 \mathrm{~h}$ in each group, cells were digested with trypsin, resuspended in serum-free medium, and the cell density was adjusted to $4 \times 10^{4}$ cells/l. One hundred microliters of cell suspension was added to the upper layer of a Transwell chamber, and $500 \mu \mathrm{l}$ of DMEM containing 10\% FBS was added to the lower layer. Following further culture in a $5 \% \mathrm{CO}_{2}$ incubator at $37 \mathrm{C}$ for $24 \mathrm{~h}$, the chamber was removed and washed three times with PBS. After wiping non-migrated cells from the upper chamber using wet cotton swabs, cells were fixed with $4 \%$ paraformaldehyde for $20 \mathrm{~min}$, and then stained with $0.1 \%$ crystal violet for $10 \mathrm{~min}$. The membrane was slightly cut using the blade at the bottom of the chamber, followed by sealing with resin. Under an inverted phase contrast microscope (200x magnification), five fields of vision were randomly selected to count the number of cells passing through the membrane.

\section{Wound healing assay}

Cells in each group were treated accordingly, then a $10-\mu$ l pipette head was used to slightly scratch along a straight line at the central axis of the culture plate. After removal of the floating cells by rinsing with PBS, plates were incubated for a further 24 and $48 \mathrm{~h}$. The distance between scratches at 0,24 , and $48 \mathrm{~h}$ was then observed un- der an optical microscope (CX23, Olympus, Japan), and the migration ability of cells in each group was expressed by the percentage of cell scratch healing. Wound healing rate $(\%)=(0 \mathrm{~h}$ width $24 \mathrm{~h}$ or $48 \mathrm{~h}$ width) $/ 0 \mathrm{~h}$ width $\times 100$.

\section{Dual-luciferase reporter assay}

A dual-luciferase reporter assay was performed with the construction of luciferase reporter gene plasmids containing potential binding sites in the 3'-untranslated region (UTR) of the EZH2 gene, including the wild-type EZH2 gene 3'-UTR and mutant EZH2 gene 3'-UTR. Plasmids were stored at $-20^{\circ} \mathrm{C}$. Plasmids containing miR-26a-5p were then co-transfected into HTR-8/SVneo cells and cultured for $48 \mathrm{~h}$, and luciferase activity was measured using a commercially available kit (Keygentec, Nanjing, China).

\section{Statistical analysis}

SPSS22.0 software (Armonk, IL, USA) was used for statistical analysis in this study. The results are expressed as mean \pm SD. Comparisons of the four diet groups were performed by one-way analysis of variance (ANOVA), and post hoc analyses were used with Tukey's test for multiple comparisons. $P$-values of less than 0.05 for ANOVA and post hoc analyses were used for assessment.

\section{Results}

\section{HE staining of placental tissue}

In placental tissue samples from the control group, villi were uniform in size, and regular in distribution and morphology. There was a monolayer distribution of villous trophoblasts, and syncytiotrophoblasts and cytotrophoblasts were rare (Figure $1 \mathrm{~A}$ ). Placental tissue from the GDM group had mature and immature areas of terminal villi. Villous trophoblasts were monolayer distributed, with an obvious increase in syncytiotrophoblasts and cytotrophoblasts compared with the control group (Figure $1 \mathrm{~A}$ ).

\section{Expression levels of SNHG6 and related genes and proteins in placental tissue}

RT-PCR showed significantly decreased expression of IncRNA SNHG 6 and EZH2 in placental tissue from the GDM group compared with that of the control group ( $p<0.001$, respectively, Figure $1 \mathrm{~B}$ ). $\mathrm{IHC}$ and WB indicated that EZH2 protein was expressed in the placental tissue from both groups of pregnant women (Figures 1 C, D). However, expression of $\mathrm{EZH} 2$ protein in the trophoblasts of the GDM group was significantly lower than in the control group, and this difference was statistically significant $(p<0.001$, respectively, Figures 1C, D). 
A
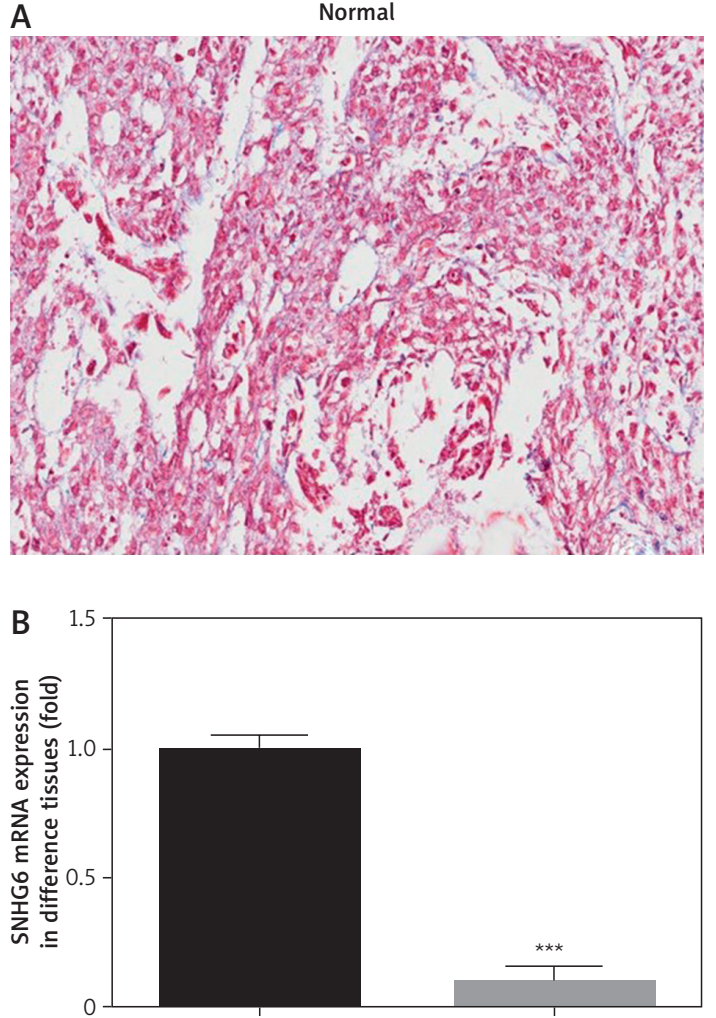

Normal

C
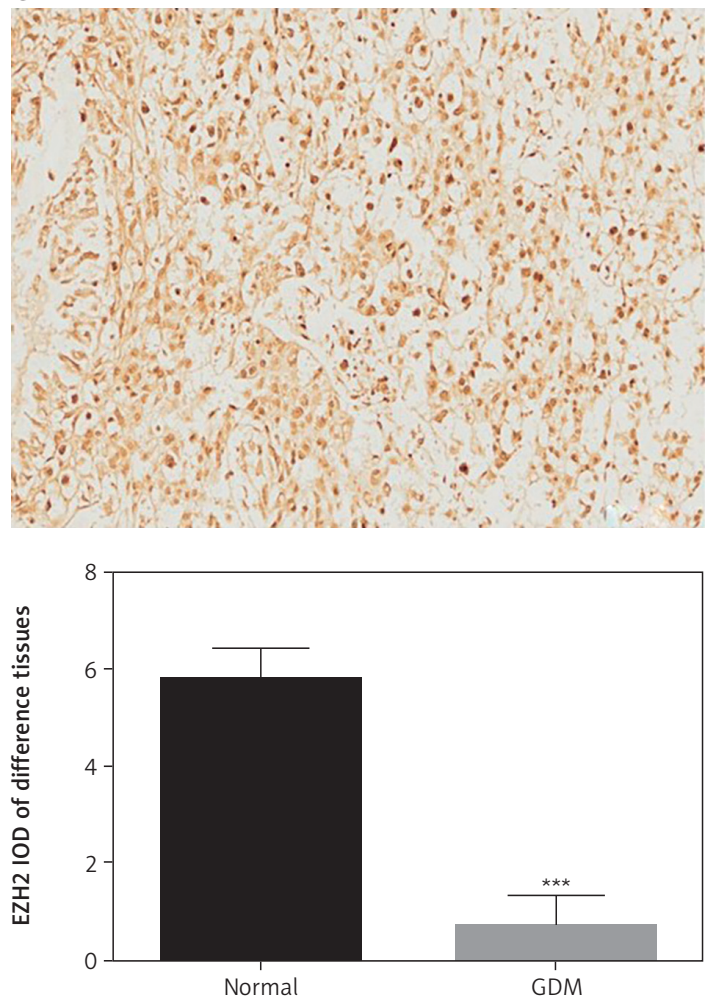

GDM
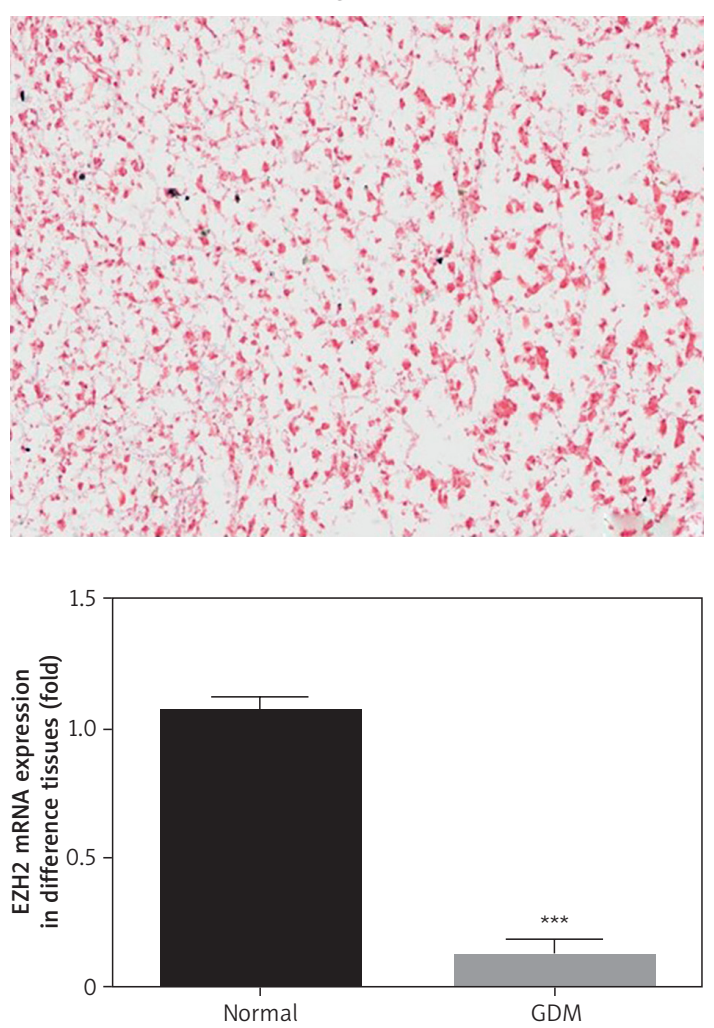

GDM

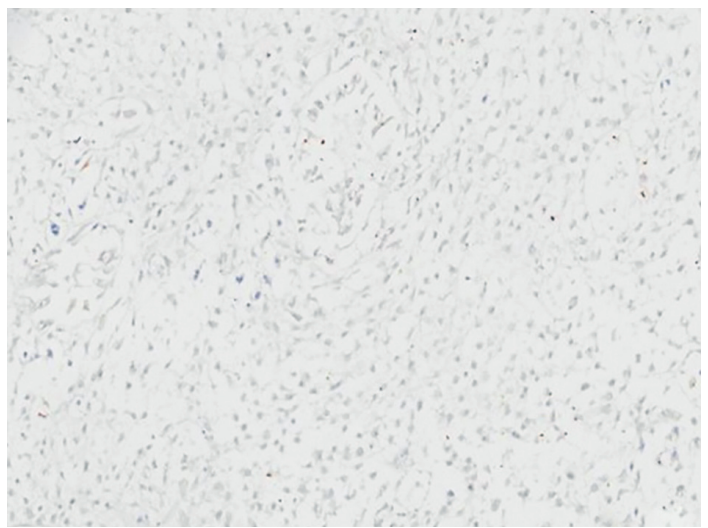

Figure 1. Placental pathology and expression of IncRNA SNHG6 and EZH2 in placental tissues from subjects with and without GDM. A - Placental pathology by HE staining (100× magnification). B - Relative mRNA expression by RT-PCR. EZH2 protein expression by IHC ( $\times 100$ magnification) (C) and WB (D)

Control - placenta from subject without GDM, GDM - placenta from subject with GDM. ${ }^{* * *} P<0.001$, compared with control. 

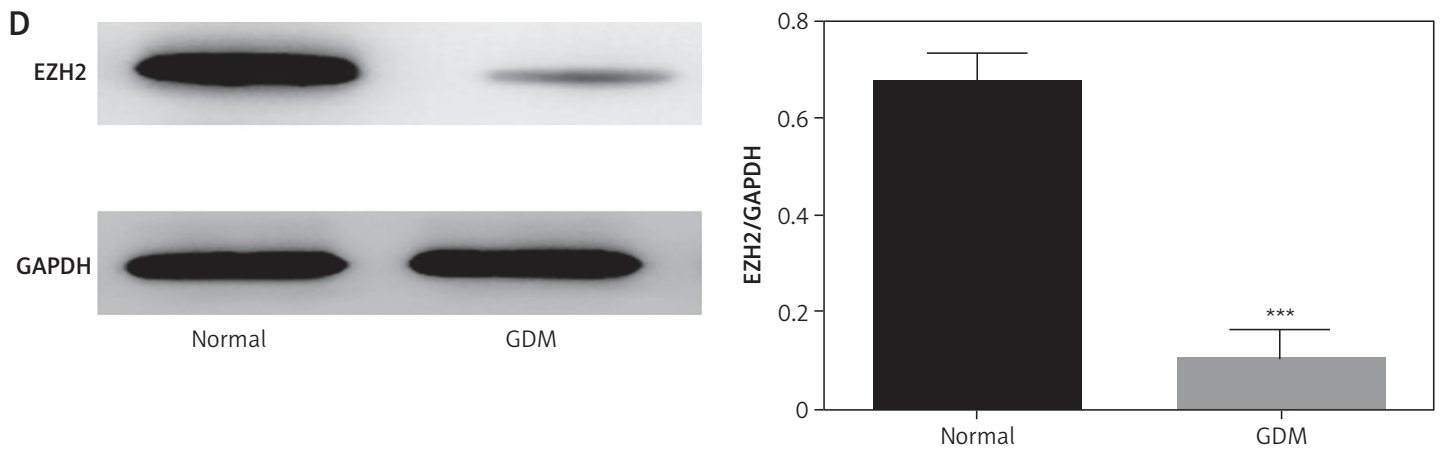

Figure 1. Cont. B - Relative mRNA expression by RT-PCR. EZH2 protein expression by IHC ( $\times 100$ magnification) (C) and WB (D)

Control - placenta from subject without GDM, GDM - placenta from subject with GDM. ${ }^{* * *} P<0.001$, compared with control.

In vitro effects of SNHG6 on expression of related genes and on cell proliferation and apoptosis

In the in vitro GDM model, RT-PCR showed that the Model group had an obvious decrease in mRNA expression of SNHG6 and EZH2 compared with the NC group $(p<0.001$, Figures $2 \mathrm{~A}, \mathrm{~B})$, but there was a significant increase in expression of miR-26a-5p mRNA $(p<0.001$, Figure $2 \mathrm{C}$ ). Compared with the Model group, the IncRNA group had a significant increase in mRNA expression of SNHG6 and EZH2 $(p<0.001$, respectively, Figures 2 A, B), but an evident decrease in miR-26a-5p mRNA expression $(p<0.001$, Figure 2 C). Furthermore, CCK-8 assays and flow cytometry analysis revealed that cell proliferation in the Model group was significantly decreased and the apoptotic rate was significantly increased compared with cells of the NC group $(p<0.001$, Figures 2 D, E). Following transfection of IncRNA SNHG6 into cells, proliferation activity significantly increased while the apoptotic rate significantly decreased compared with cells of the Model group ( $p<0.001$, Figures 2 D, E).

\section{Effect of SNHG6 on cell invasion and migration in vitro}

Compared with the NC group, the number of invasive cells in the Model group was significantly reduced, and the wound healing rate of Model group cells was inhibited at 24 and $48 \mathrm{~h}(p<0.001$, Figures 3 A, B). Transfection of IncRNA SNHG6 into cells (IncRNA group) resulted in a significantly higher number of invasive cells than in the Model group, and a significant increase in the wound healing rate of cells at 24 and $48 \mathrm{~h}(p<0.001$, Figures $3 \mathrm{~A}, \mathrm{~B})$.

\section{In vitro effect of SNHG6 on expression of related proteins}

WB revealed decreased expression of EZH2 and H3K27me3 proteins in the Model group compared with the NC group ( $p<0.001$, Figure 4). Transfection of IncRNA SNHG6 into cells (IncRNA group) resulted in significantly increased expression of EZH2 and $\mathrm{H} 3 \mathrm{~K} 27 \mathrm{me} 3$ proteins compared with that of the Model group ( $p<0.001$, respectively, Figure 4$)$.

Gene expression, cell proliferation, and apoptosis in each in vitro experimental group

RT-PCR was used to analyze gene expression of IncRNA SNHG6, EZH2, and miRNA-26a-5p. Compared with the NC group, the Model group and miR-inhibitor group had evidently decreased expression of IncRNA SNHG6 $(p<0.001$, respectively, Figure $5 \mathrm{~A}$ ). The Model group also showed decreased gene expression of EZH2 $(p<0.001$, Figure $5 \mathrm{~B}$ ), and significantly increased gene expression of miR-26a-5p ( $p<0.001$, Figure $5 \mathrm{C}$ ). Furthermore, compared with the Model group, the IncRNA + miRNA group had significantly increased gene expression of IncRNA SNHG6 $(p<0.001$, Figure $5 \mathrm{~A}$ ), and the miR-inhibitor group exhibited much higher gene expression of EZH2 but obviously lower gene expression of miR-26a-5p $(p<0.001$, respectively, Figures 5 B, C). Co-transfection of IncRNA SNHG6 and miRNA-26a-5p into cells (IncRNA + miRNA group) resulted in a significant decrease in gene expression of EZH2 and an obvious increase in expression of miR-26a-5p compared with that in the miR-inhibitor group $(p<0.001$, Figures $5 \mathrm{~B}, \mathrm{C})$.

Using the CCK-8 assay, the Model group exhibited a decrease in cell proliferation activity compared with that of the NC group (Figure $5 \mathrm{D}$ ). When the miR-26a-5p inhibitor was transfected into cells (miR-inhibitor group), there was an increase in cell proliferation compared with that of the Model group (Figure $5 \mathrm{D}$ ). Co-transfection of IncRNA SNHG6 and miRNA-26a-5p into cells (IncRNA + miRNA group) resulted in significantly lower cell proliferation activity than that observed 

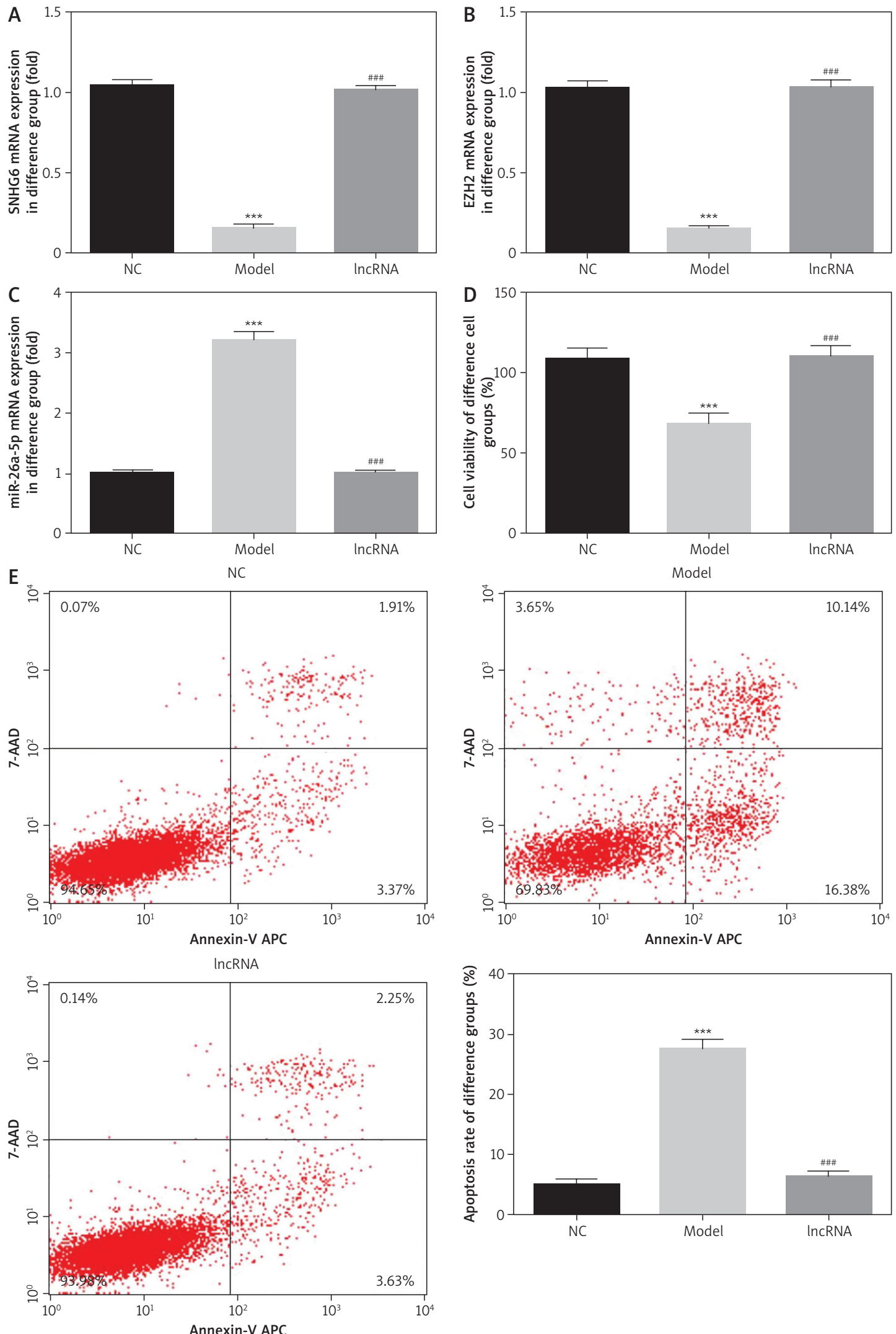

Figure 2. Relative mRNA expression, cell proliferation, and apoptosis rate of different experimental groups in an in vitro cell model of GDM. A - SNHG6 mRNA expression by RT-PCR assay. B - EZH2 mRNA expression by RT-PCR assay. C - miR-26a-5p mRNA expression by RT-PCR assay. D - Cell viability by CCK-8 assay. E - Apoptosis rate

NC-normal control group, Model - cells treated with high-dose glucose, IncRNA - cells transfected with IncRNA SNHG6

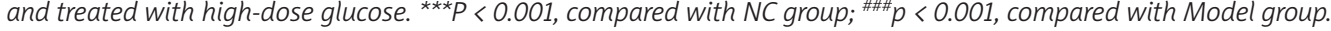




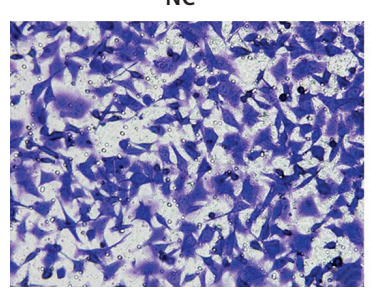

Model
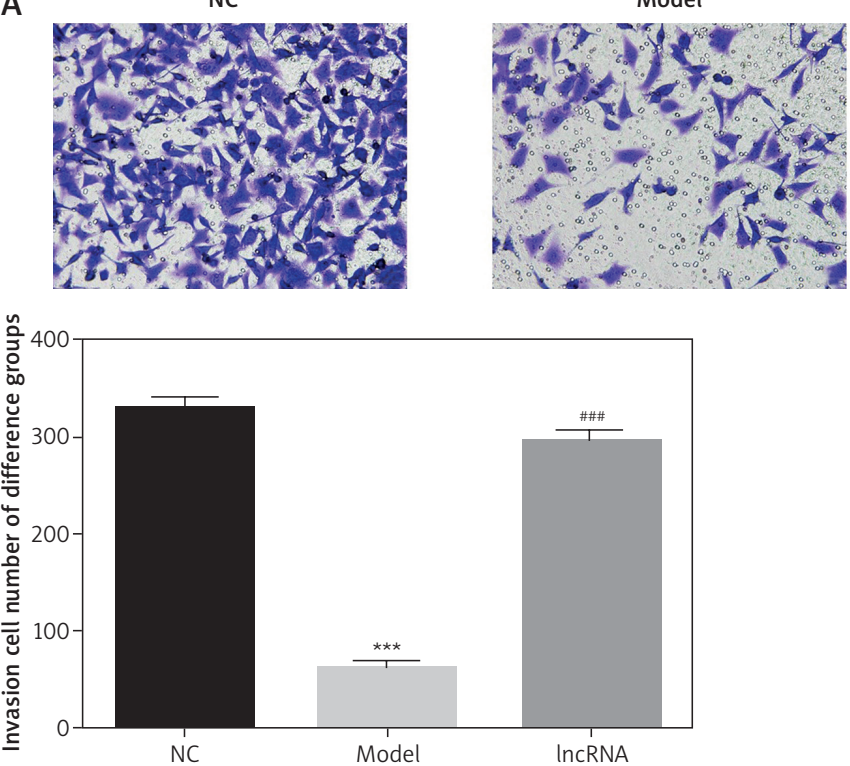

B

NC
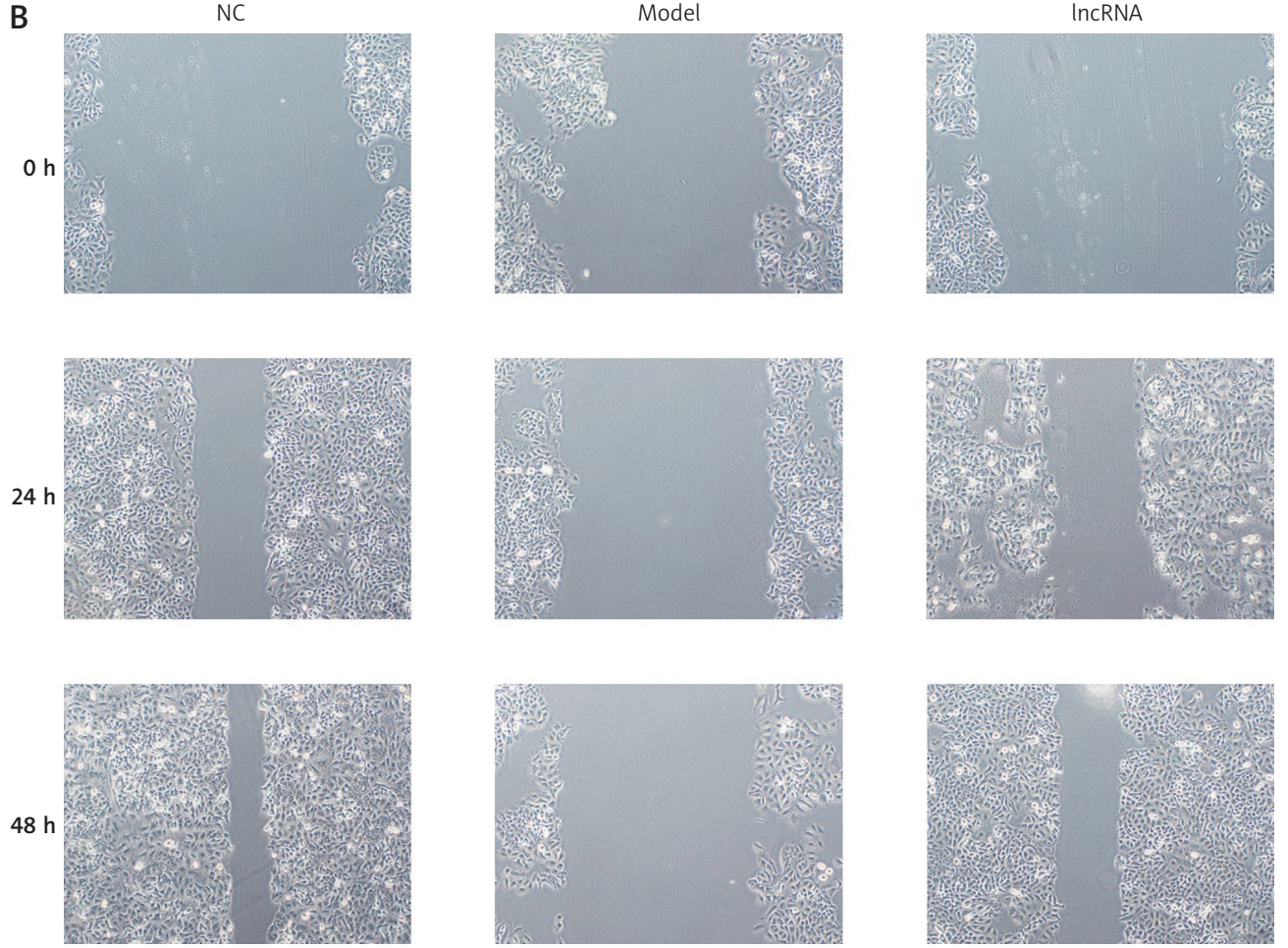

IncRNA

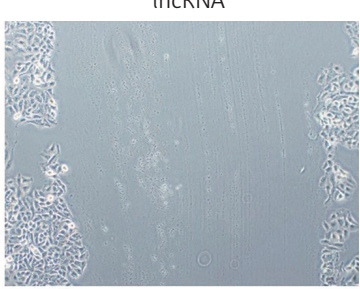

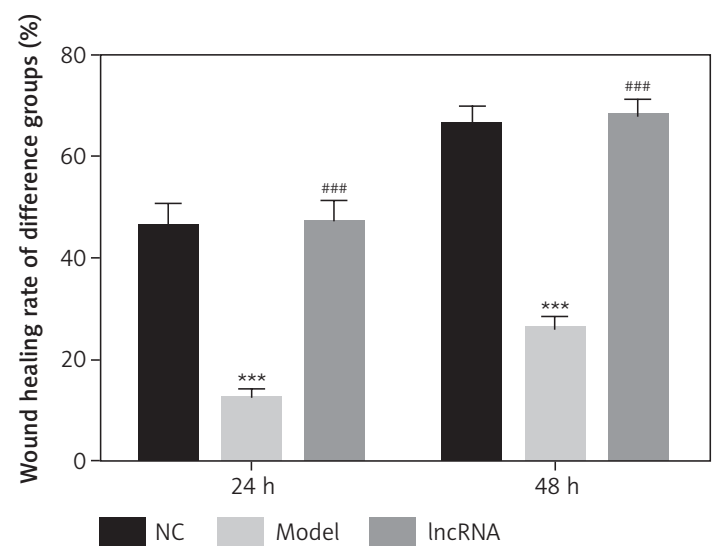

Figure 3. Invasion and migration abilities of cells of different experimental groups. A - Invasion assessed by transwell assay (200x). B - Wound healing rate assessed by wound healing assay (100x) $N C$ - normal control group, Model - cells treated with high-dose glucose, IncRNA - cells transfected with InCRNA SNHG6 and treated with high-dose glucose. ${ }_{* * *} P<0.001$, compared with NC group; \#\#\#p $<0.001$, compared with Model group. 
$\mathrm{EZH} 2$

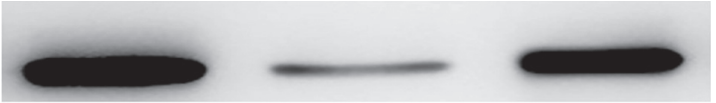

H3K27me3

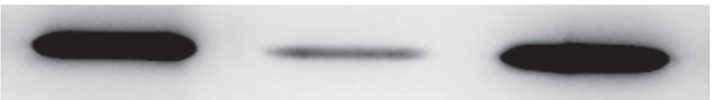

GAPDH
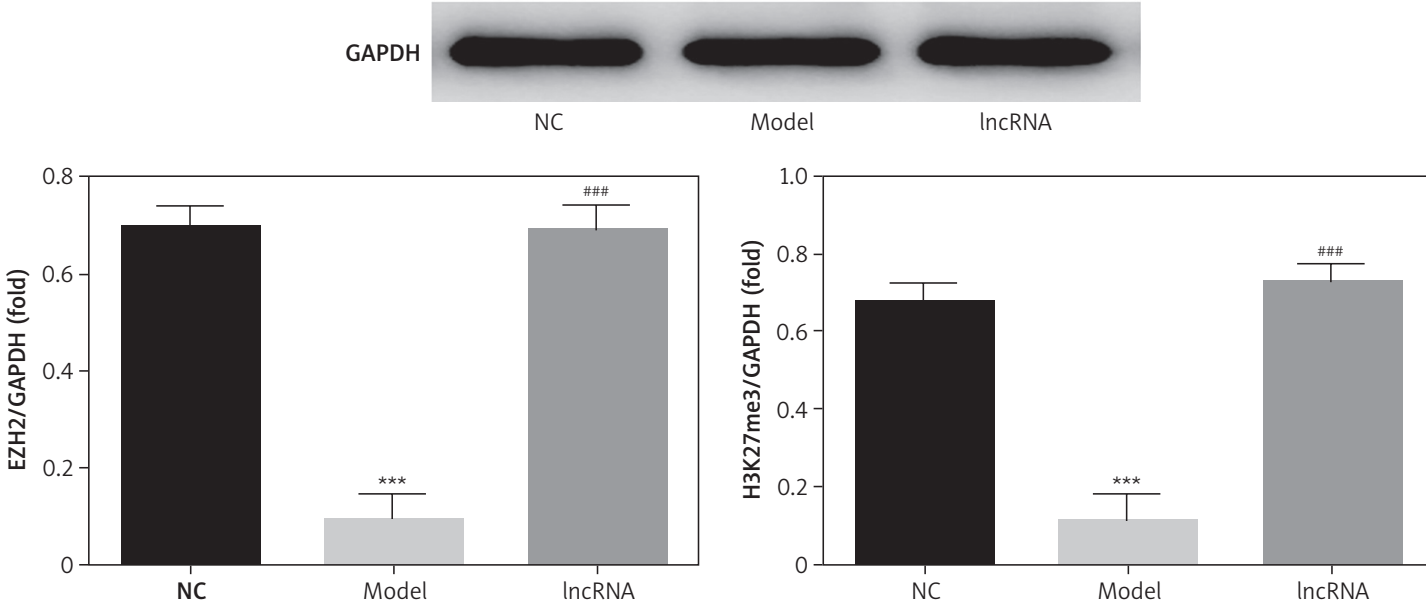

Figure 4. Relative protein expression, determined by WB, of different experimental groups in an in vitro cell model of GDM

NC-normal control group, Model - cells treated with high-dose glucose, IncRNA - cells transfected with IncRNA SNHG6 and treated with high-dose glucose. ${ }^{* *} P<0.001$, compared with NC group, ${ }^{\# \# P}<0.001$, compared with Model group.

in the miR-inhibitor group ( $p<0.001$, Figure $5 \mathrm{D}$ ). Meanwhile, flow cytometry analysis demonstrated an obvious decrease in the apoptosis rate in the Model group compared with that of the NC group, while the apoptosis rate was significantly increased in the miR-inhibitor group compared with that of the Model group (Figure $5 \mathrm{E}$ ). Cotransfection of IncRNA SNHG6 and miRNA-26a-5p into cells (IncRNA + miRNA group) resulted in an obvious decrease in apoptosis rate when compared with the miR-inhibitor group $(p<0.001$, Figure $5 \mathrm{E}$ ).

\section{Cell invasion and migration abilities in each} in vitro experimental group

Transwell assays were used to investigate cell invasion in the different experimental groups. Compared with the NC group, the Model group had significantly fewer invasive cells, while the number of invasive cells in the miR-inhibitor group was obviously upregulated compared with the Model group (Figure 6 A). Co-transfection of IncRNA SNHG6 and miRNA-26a-5p into cells (IncRNA + miRNA group) resulted in a decrease in the number of invasive cells when compared with the miR-inhibitor group ( $p<0.001$, Figure 6 A). The wound healing assay revealed that the rate of wound healing was sig- nificantly decreased at 24 and $48 \mathrm{~h}$ in the Model group compared with that of the NC group. Transfection of the miR-26a-5p inhibitor into cells (miRinhibitor group) resulted in an obvious increase in wound healing rate at both time points compared with the rates in the Model group. Following cotransfection of IncRNA SNHG6 and miRNA-26a-5p into cells (IncRNA + miRNA group), there was a significant decrease in the wound healing rate at 24 and $48 \mathrm{~h}$ compared with that of the miR-inhibitor group $(p<0.001$, Figure $6 \mathrm{~B})$.

\section{WB detection of related protein expression in each in vitro experimental group}

WB revealed obvious downregulation in expression levels of $\mathrm{EZH} 2$ and $\mathrm{H} 3 \mathrm{~K} 27$ me 3 proteins in the Model group when compared with those in the NC group. Transfection of miR-26a-5p inhibitor (miR-inhibitor group) resulted in an increase in protein expression of $\mathrm{EZH} 2$ and $\mathrm{H} 3 \mathrm{~K} 27$ me 3 when compared with expression levels in the Model group. Cells co-transfected with IncRNA SNHG6 and miRNA-26a-5p (IncRNA + miRNA group) exhibited significant decreases in EZH2 and H3K27me3 protein expression when compared with levels in the miR-inhibitor group $(p<0.001$, respectively, Figure 7). 


\section{Correlation analysis of miR-26a-5p and EZH2}

The dual-luciferase reporter assay demonstrated that there was no significant difference in luciferase activity between the miR-NC group and the miR-26a-5p group in EZH2-Mul cells. However, in EZH2-WT cells, the miR-26a-5p group had significantly reduced luciferase activity compared with that of the miR-NC group $(p<0.001$, Figure 8$)$.

\section{Discussion}

GDM is a common disease in pregnancy, and one of the risk factors of adverse events in pregnant women and fetuses. There has been increased focus on epigenetic studies of GDM and IncRNA in recent decades. LncRNA H19 was the first IncRNA reported to be associated with GDM, and may cause insulin secretion restriction by affecting the function of islet cells [10]. Abnormal expression of IncRNAs is reported to be intimately associated with the occurrence of GDM and can affect the status of placental cells during pregnancy $[11,12]$. In our study, expression of IncRNA SNHG6 in the placenta of patients with
GDM was abnormally low, suggesting that IncRNA SNHG6 may be involved in the pathogenesis of GDM. Furthermore, in an in vitro model of GDM, transfection of IncRNA SNHG6 into HTR-8/SVneo cells resulted in effective inhibition of the damaging activity (proliferation, invasion and migration) caused by high-dose glucose stimulation. Simultaneously, expression of miR-26a-5p decreased significantly with the increase in IncRNA SNHG6 expression. It was thus speculated that IncRNA SNHG6 might act through miR-26a-5p.

MicroRNAs (miRNAs) are a class of highly conserved, small non-coding RNAs that have unique functions at the post-transcriptional level (epigenetics). Studies have shown that miRNAs are closely related to many important physiological and pathological processes in vivo and play a "dynamic regulator" role in cell function and metabolic regulation [17]. Correlation between miRNAs and GDM is a relatively new area of research and, to date, there are only limited studies with small sample sizes reporting on this correlation [18, 19]. However, there are some in vitro and simulation experiments that provide theoretical support for
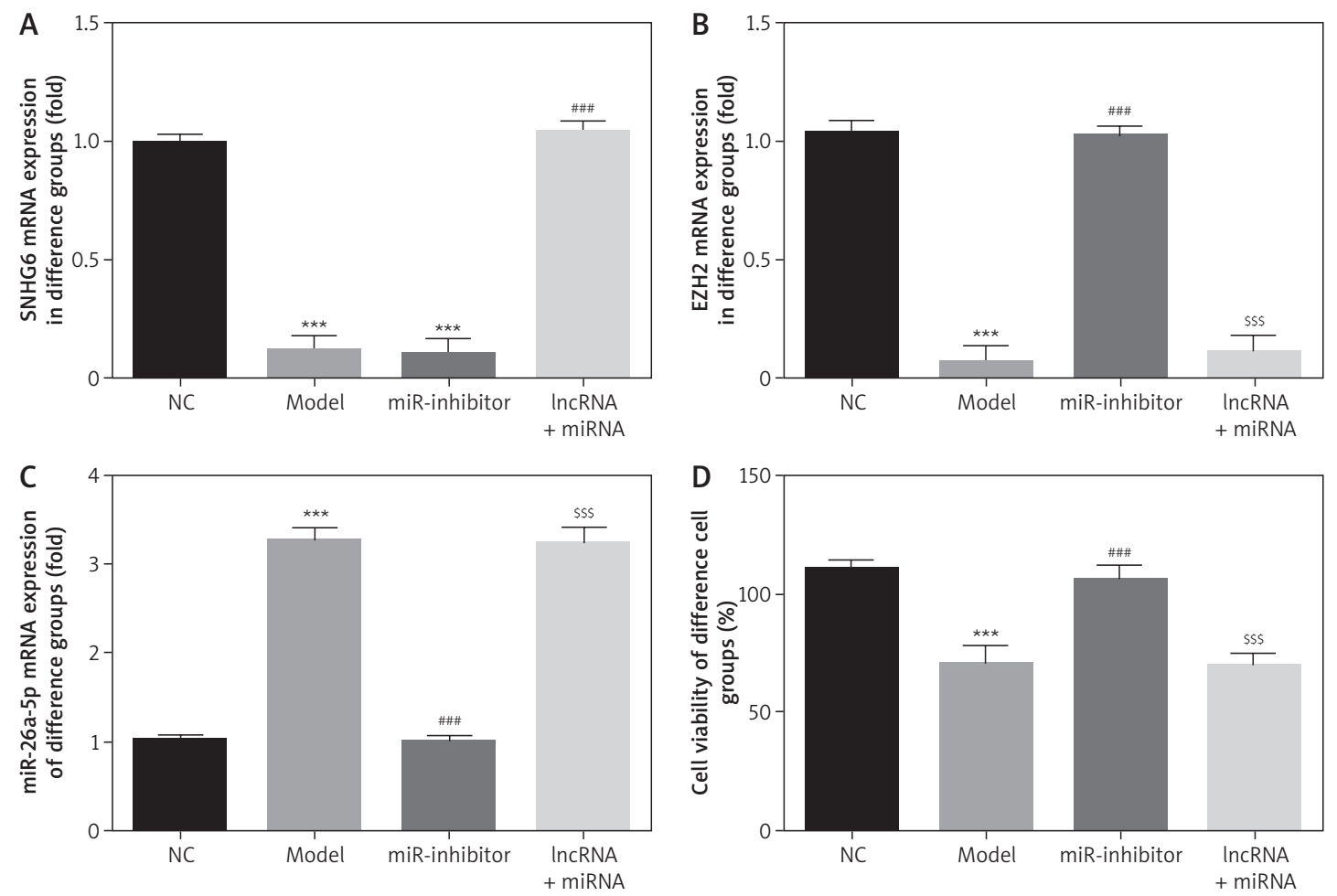

Figure 5. Effects of miRNA-26a-5p on relative mRNA expression, cell proliferation, and apoptosis rate of different experimental groups in an in vitro cell model of GDM. A - SNHG6 mRNA expression by RT-PCR assay. B - EZH2 mRNA expression by RT-PCR assay. C - miRNA-26a-5p mRNA expression by RT-PCR assay. D - Cell viability determined by CCK-8 assay

$N C$ - normal control group, Model - cells treated with high-dose glucose; miR-inhibitor: cells transfected with miRNA26a-5p inhibitor and treated with high-dose glucose, IncRNA + miRNA: cells transfected with IncRNA SNHG6 and miRNA-26a-5p and treated with high-dose glucose. ${ }^{* * *} P<0.001$, compared with NC group, ${ }^{\# \#} p<0.001$, compared with Model group, ${ }^{\$ \$} p<0.001$, compared with miR-inhibitor group. 
$\mathrm{E}$
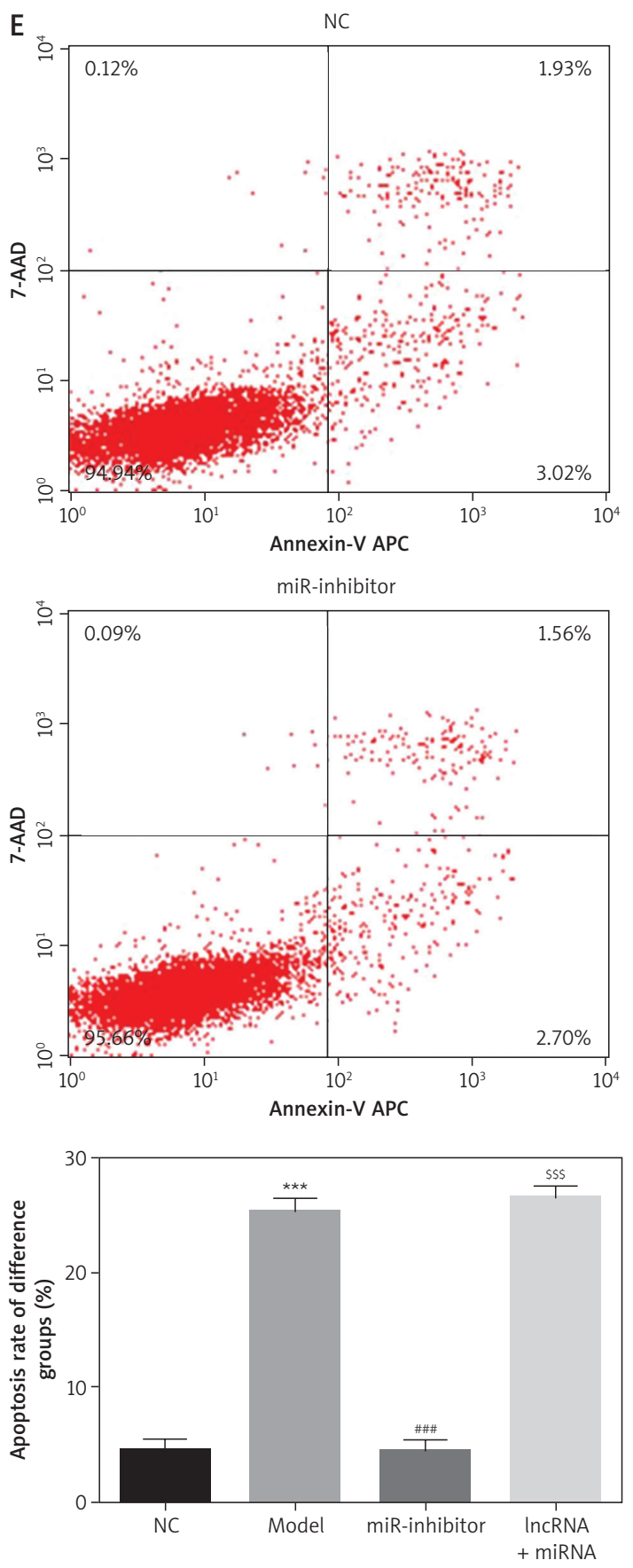

these studies [20]. In our study, miR-26a-5p played an important role with IncRNA SNHG6 in improving the pathogenesis of GDM. Silencing miR-26a$5 p$ could effectively alleviate the symptoms of GDM, whereas the positive role of SNHG6 disappeared after co-transfecting miR-26a-5p while overexpressing IncRNA SNHG6. This suggests that SNHG6 may improve the symptoms of GDM by inhibiting miR-26a-5p. Meanwhile, our study also demonstrated a significant increase in EZH2 protein and gene expression with overexpression of SNHG6 and suppressed expression of miR-26a-5p.
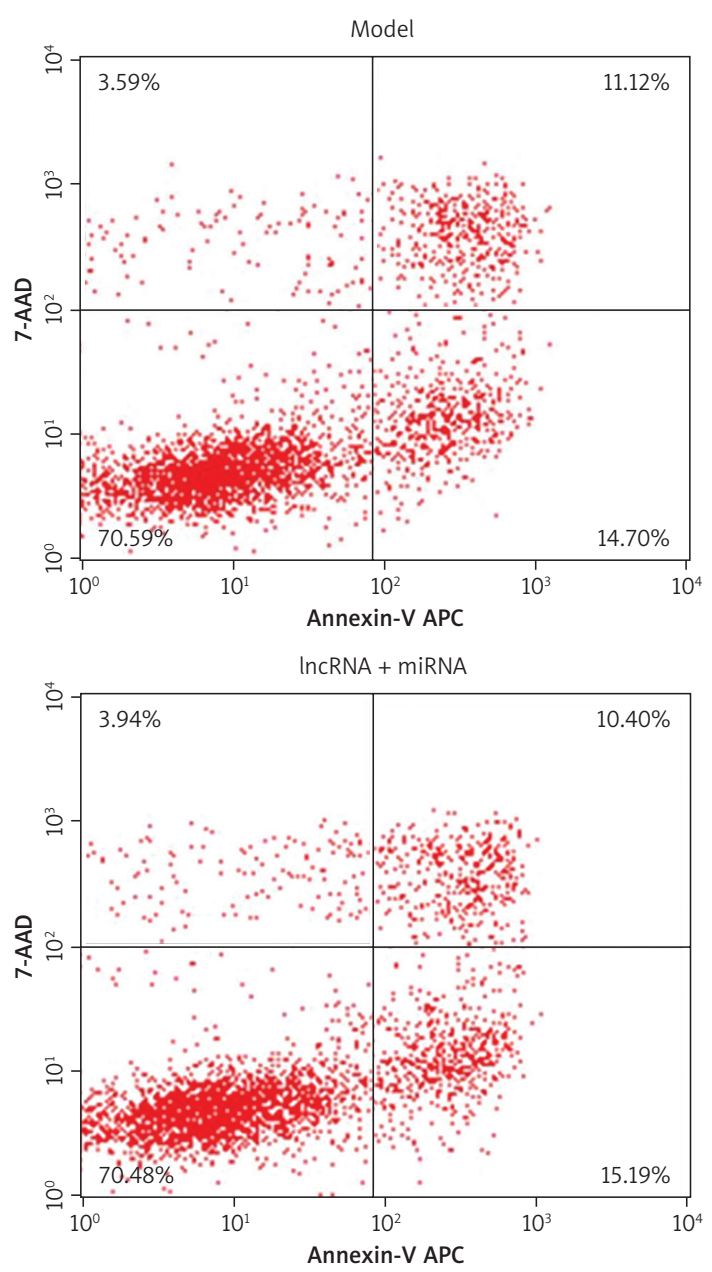

Figure 5. Cont. E - Apoptosis rate determined by flow cytometry

NC - normal control group, Model - cells treated with high-dose glucose; miR-inhibitor: cells transfected with miRNA-26a-5p inhibitor and treated with high-dose glucose, IncRNA + miRNA: cells transfected with IncRNA SNHG6 and miRNA-26a-5p and treated with high-dose glucose. ${ }^{* * *} p<0.001$, compared with NC group, \#\#p<0.001, compared with Model group, ${ }^{\$ S S} p<0.001$, compared with miRinhibitor group.
It was confirmed by dual-luciferase reporter gene assay that mir-26a-5p can target EZH2 in HTR-8/ SVneo cells, and the abnormal expression of EZH2 may be related to the occurrence of GDM-induced placental villous cell function.

$\mathrm{EZH} 2$ is the catalytic core protein in polycomb repressive complex 2 (PRC2), which catalyzes and maintains trimethylation of histone $\mathrm{H} 3$ at lysine 27 (H3K27me3). This methylation site is an epigenetic marker related to gene silencing. A decrease in EZH2-H3K27me3 expression can inhibit cell proliferation and affect tumor progression in 

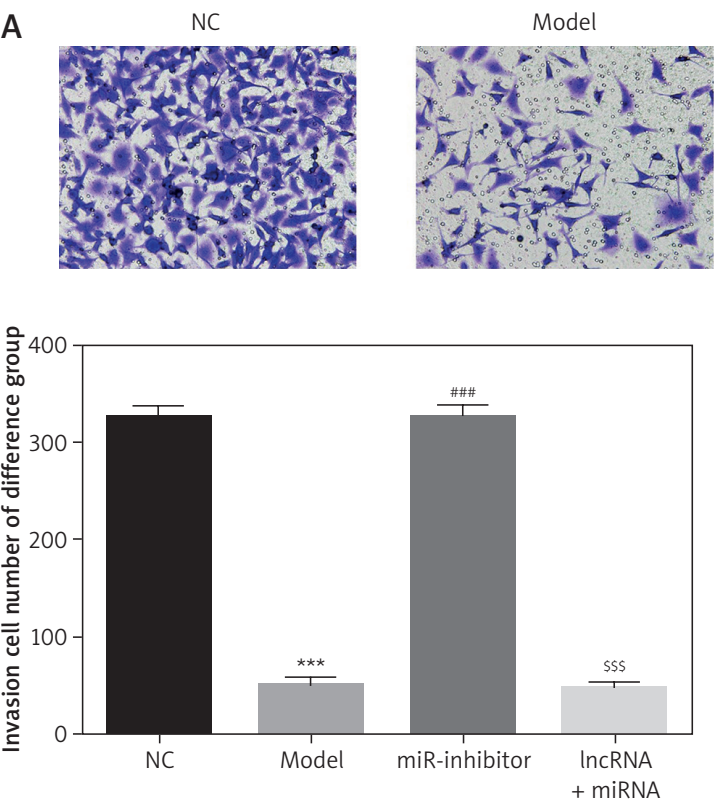

B
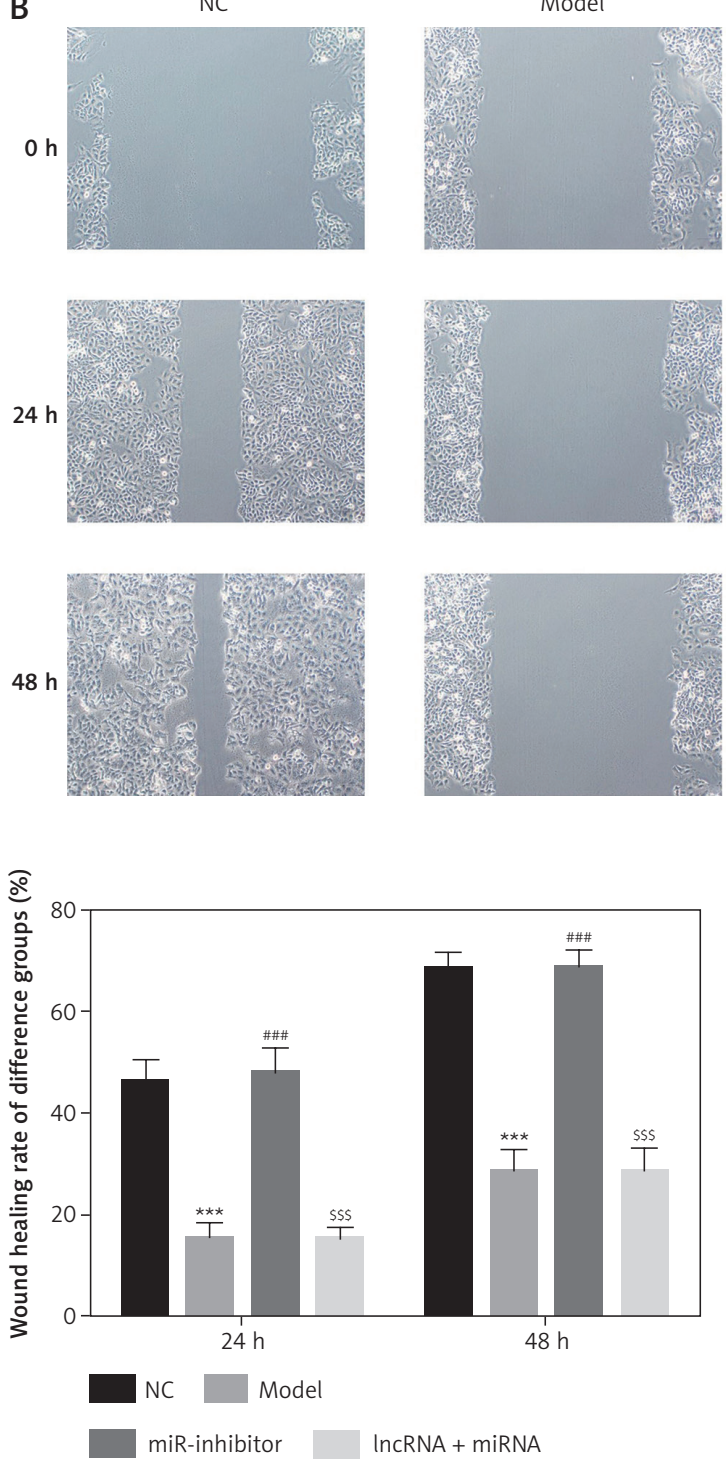

miR-inhibitor
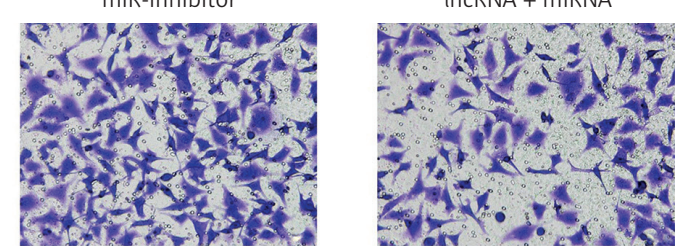

miR-inhibitor
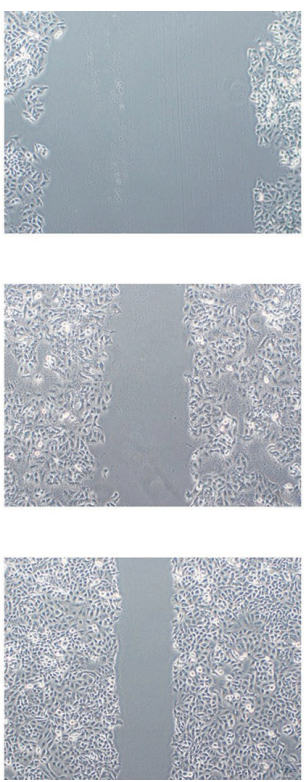

IncRNA + miRNA
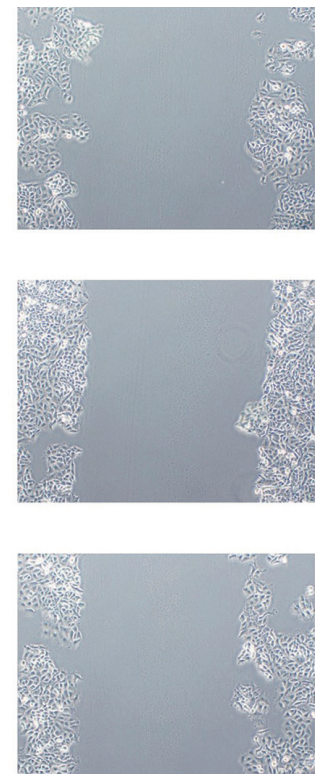

Figure 6. Effects of miRNA-26a-5p on invasion and migration of cells of different experimental groups in an in vitro cell model of GDM. A - Cell invasion assessed by transwell assay (200x). B - Cell migration (wound healing rate) assessed by wound healing assay (100x)

NC - normal control group, Model - cells treated with high-dose glucose, miR-inhibitor - cells transfected with miRNA-26a-5p inhibitor and treated with high-dose glucose, InCRNA + MiRNA - cells transfected with IncRNA SNHG6 and miRNA-26a-5p and treated with high-dose glucose. ${ }^{* * *} P<0.001$, compared with NC group, ${ }^{\# \# p}<<0.001$, compared with Model group, ${ }^{\$ \$} p<0.001$, compared with miRinhibitor group. 
$\mathrm{EZH} 2$

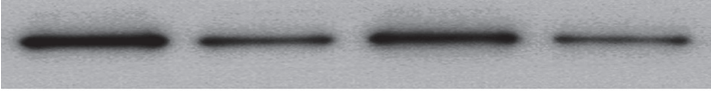

H3K27me3

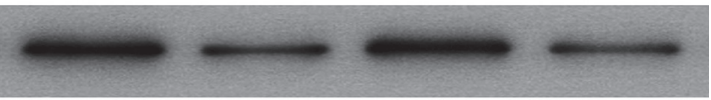

GAPDH

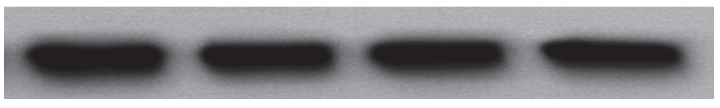

NC

Model miR-inhibitor IncRNA + miRNA
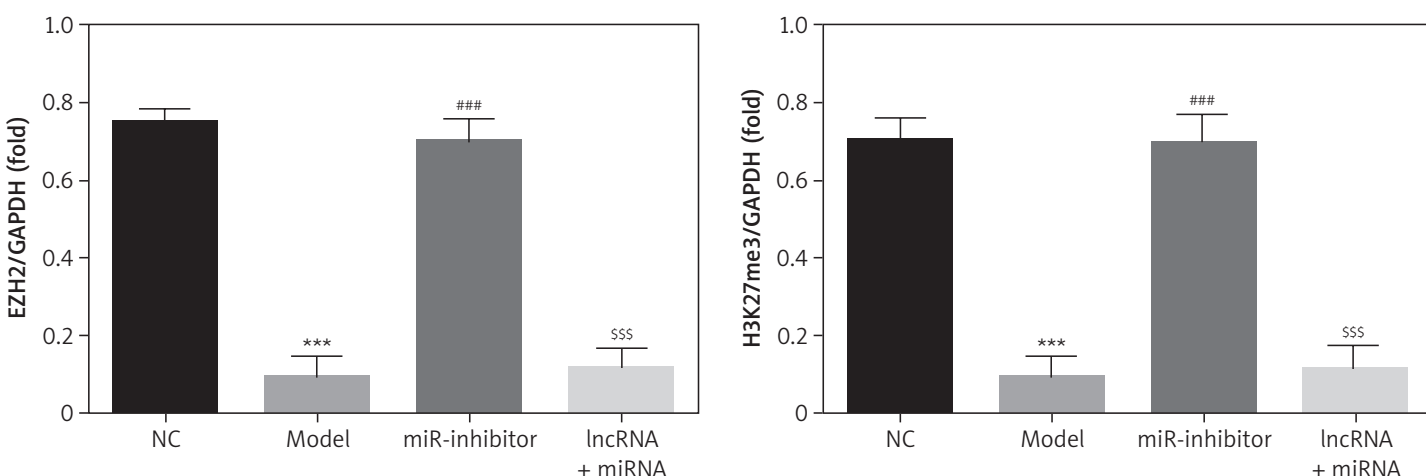

Figure 7. Effect of miRNA-26a-5p on relative expression of proteins as assessed by WB

NC - normal control group, Model - cells treated with high-dose glucose, miR-inhibitor - cells transfected with miRNA-26a-5p inhibitor and treated with high-dose glucose, IncRNA + miRNA - cells transfected with IncRNA SNHG6 and miRNA-26a-5p and treated with high-dose glucose. ${ }^{* * *} p<0.001$, compared with NC group, ${ }^{\# \#} p<0.001$, compared with Model group, ${ }^{\$ \$ \$} p<0.001$, compared with miR-inhibitor group.

\begin{tabular}{|l|ll|l|l|l|l|l|l|}
\hline $\begin{array}{l}\text { Position 250-257 of EZH2 3'UTR } \\
\text { hsa-miR-26-5p }\end{array}$ & $\begin{array}{l}\text { 5' } \\
\text { 3'...ACUUUGAAUAAAGAAUACUUGAA }\end{array}$ & $8 \mathrm{mer}$ & -0.58 & 99 & -0.58 & 4.646 & 0.85 \\
\hline
\end{tabular}

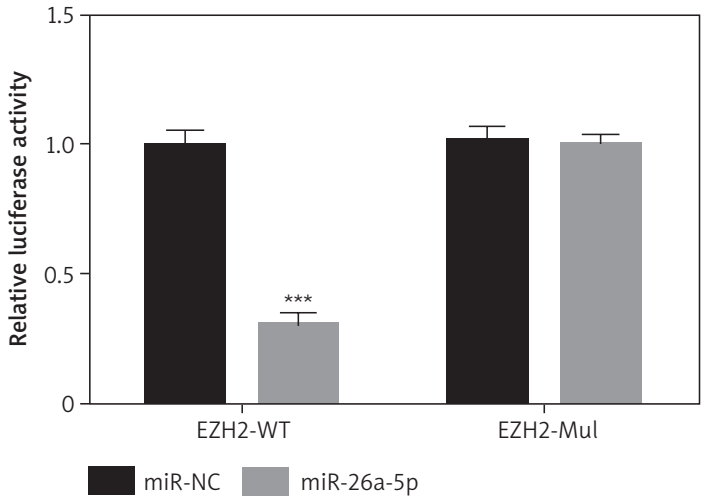

lung cancer, bladder transitional cell carcinoma, and embryonal rhabdomyosarcoma. Inhibition of the EZH2-H3K27me3 pathway enhanced chemosensitivity to fluorouracil in hepatoma cells [21]. Siddiqi et al. [22] reported that regulation of the EZH2-H3K27me3 pathway could reduce expression of endogenous antioxidant inhibitor thioredoxin interaction protein (TXNIP), suppress the oxidative stress response, and alleviate proteinuria and other symptoms, so as to regulate the progress of diabetic nephropathy at the epigenetic level. In the
Figure 8. Correlation between miRNA-26a-5p and EZH2

${ }^{* * *} P<0.001$, compared with miR-NC group. 
tion, invasion, and migration ability of trophoblasts by regulating the miR-26a-5p/EZH2-H3K27me3 pathway. The findings of this study suggest that IncRNA SNHG6 may be an essential factor in the prevention of GDM and could facilitate the development of novel therapeutics for GDM to secure the outcome of future generations.

\section{Conflict of interest}

The authors declare no conflict of interest.

\section{References}

1. Hanson MA, Bardsley A, De-Regil LM, et al. The International Federation of Gynecology and Obstetrics (FIGO) Recommendations on adolescent, preconception, and maternal nutrition: "think nutrition first". Int J Gynaecol Obstet 2015; 131 Suppl 4: S213-53.

2. Abouzeid M, Versace VL, Janus ED, et al. Socio-cultural disparities in GDM burden differ by maternal age at first delivery. PLoS One 2015; 10: e0117085.

3. Assaf-Balut C, García de la Torre N, Durán A, et al. A Mediterranean diet with additional extra virgin olive oil and pistachios reduces the incidence of gestational diabetes mellitus (GDM): a randomized controlled trial: The St. Carlos GDM prevention study. PLoS One 2017; 12: e0185873.

4. Lu D, Yang M, Yao Y, Xie Y. A clinical research study on the respective relationships between visfatin and human fetuin $A$ and pregnancy outcomes in gestational diabetes mellitus. Taiwan J Obstet Gynecol 2019; 58: 808-13.

5. Hepp P, Hutter S, Knabl J, et al. Histone H3 Lysine 9 acetylation is downregulated in gdm placentas and calcitriol supplementation enhanced this effect. Int J Mol Sci 2018; 19: E4061.

6. Moen GH, Sommer C, Prasad RB, et al. Epigenetic modifications and gestational diabetes: a systematic reviewer of published literature. Eur J Endocrinol 2017; 176: R247-67.

7. Szemraj-Rogucka ZM, Szemraj J, Masiarek K, Majos A. Circulating microRNAs as biomarkers for myocardial fibrosis in patients with left ventricular non-compaction cardiomyopathy. Arch Med Sci 2019; 15: 376-84.

8. Abdelsalam L, Ibrahim AA, Shalaby A, et al. Expression of miRNAs-122, -192 and -499 in end stage renal disease associated with acute myocardial infarction. Arch Med Sci 2019; 15: 1247-53.

9. Ding Y, Wang X, Pan J, et al. Aberrant expression of long non-coding RNAs (InCRNAs) is involved in brain glioma development. Arch Med Sci 2019; 16: 177-88.

10. Xu M, Chen X, Lin $\mathrm{K}$, et al. IncRNA SNHG6 regulates EZH2 expression by sponging miR-26a/b and miR-214 in colorectal cancer. J Hematol Oncol 2019; 12: 3.

11. Li Y, Li D, Zhao M, et al. Long noncoding RNA SNHG6 regulates p21 expression via activation of the JNK pathway and regulation of EZH2 in gastric cancer cells. Life Sci 2018; 208: 295-304.

12. Zhang M, Duan W, Sun W. LncRNA SNHG6 promotes the migration, invasion, and epithelial-mesenchymal transition of colorectal cancer cells by miR-26a/EZH2 axis. Onco Targets Ther 2019; 12: 3349-60.

13. Ding GL, Wang FF, Shu J, et al. Transgenerational glucose intolerance with Igf2/H19 epigenetic alterations in mouse islet induced by intrauterine hyperglycemia. Diabetes 2012; 61: 1133-42.
14. Hamlett WC. Ultrastructure of the maternal-fetal interface of the yolk sac placenta in sharks. Ital J Anat Embryol 2005; 110 (2 Suppl 1): 175-81.

15. Zhang Y, Wu H, Wang F, Ye M, Zhu H, Bu S. Long noncoding RNA MALAT1 expression in patients with gestational diabetes mellitus. Int I Gynaecol Obstet 2018; 140: 164-9.

16. Shi Z, Zhao C, Long W, Ding H, Shen R. Microarray expression profile analysis of long non-coding RNAs in umbilical cord plasma reveals their potential role in gestational diabetes-induced macrosomia. Cell Physio Biochem 2015; 36: 542-54.

17. Vienberg S, Geiger J, Madsen S, Dalgaard LT. MicroRNAs in metabolism. Acta Physiol 2017; 219: 346-61.

18. Deiuliis JA. MicroRNAs as regulators of metabolic disease: pathophysiologic significance and emerging role as biomarkers and therapeutics. Int J Obes 2016; 40: 88-101.

19. Zhu Y, Tian F, Li H, Zhou Y, Lu J, Ge Q. Profiling maternal plasma microRNA expression in early pregnancy to predict gestational diabetes mellitus. Int J Gynaecol Obstet 2015; 130: 49-53.

20. Aires MB, Dos Santos AC. Effects of maternal diabetes on trophoblast cells. World I Diabetes 2015; 6: 338-44.

21. Vella S, Pomella S, Leoncini PP, et al. MicroRNA-101 is repressed by EZH2 and its restoration inhibits tumorigenic features in embryonal rhabdomyosarcoma. Clin Epigenetics 2015; 7: 82

22. Siddiqi FS, Majumder S, Thai K, et al. The histone methyltransferase enzyme enhancer of zeste homolog 2 protects against podocyte oxidative stress and renal injury in diabetes. J Am Soc Nephrol 2016; 27: 2021-34. 